\title{
Probiotics to prevent necrotising enterocolitis and nosocomial infection in very low birth weight preterm infants
}

\author{
J. Uberos $^{1,2 *}$, E. Aguilera-Rodríguez ${ }^{2}$, A. Jerez-Calero ${ }^{2}$, M. Molina-Oya ${ }^{2}$, A. Molina-Carballo ${ }^{1,2}$ and \\ E. Narbona-López ${ }^{1}$ \\ ${ }^{1}$ Medicine Faculty, Avda. de la investigación 11, 18016 Granada, Spain \\ ${ }^{2}$ Neonatal Intensive Care Unit, San Cecilio Clinical Hospital, Avda. Dr. Oloriz 16, 18012 Granada, Spain
}

(Submitted 5 January 2017 - Final revision received 1 March 2017 - Accepted 6 March 2017 - First published online 26 April 2017)

\section{Abstract}

The aim of the study was to determine whether routine probiotic supplementation (RPS) with Lactobacillus rhamnosus GG (LGG) or Lactobacillus acidophilus + Lactobacillus bifidum is associated with reduced risk of necrotising enterocolitis (NEC) $\geq$ Stage II in preterm neonates born at $\leq 32$ weeks' gestation. We conducted a retrospective cohort study on the effect of probiotic supplementation in very low birth weight infants in our neonatal unit by comparing two periods: before and after supplementation. The incidence of NEC $\geq$ Stage II, late-onset sepsis and all-cause mortality was compared for an equal period 'before' (Period I) and 'after' (Period II) RPS with $L G G$ or L. acidophillus + L. bifidum. Multivariate logistic regression analysis was conducted to adjust for relevant confounders. The study population was composed of 261 neonates (Period I $v$. II: $134 v$. 127) with comparable gestation duration and birth weights. In $<32$ weeks, we observed a significant reduction in NEC $\geq$ Stage II (11.3 v. 4.8\%), late-onset sepsis (16v. 10.5\%) and mortality (19.4 $v$. 2.3\%). The benefits in neonates aged $\leq 27$ weeks did not reach statistical significance. RPS with $L G G$ or $L$. acidophillus $+L$. bifidum is associated with a reduced risk of $\mathrm{NEC} \geq$ Stage II, late-onset sepsis and mortality in preterm neonates born at $\leq 32$ weeks' gestation.

Key words: Probiotics: Lactobacillus rhamnosus GG: Lactobacillus acidophillus: Lactobacillus bifidum: Necrotising enterocolitis: Very low birth weight infants: Late-onset sepsis

Necrotising enterocolitis (NEC) is the most common gastrointestinal pathology in very low birth weight (VLBW) infants. It is associated with neurodevelopmental disorders ${ }^{(1)}$ and an increase of $10-30 \%$ in related mortality ${ }^{(2)}$. Strategies for preventing preterm birth and its consequences, including the use of antenatal steroids, have had very limited effect in reducing the risk of NEC, although a notable impact on lung immaturity has been reported ${ }^{(3)}$. Preferential breast-feeding and the fact that most neonatal units have developed standardised nutrition protocols have been epidemiologically associated with a reduced risk of $\mathrm{NEC}^{(4)}$.

Bacteria from human milk are among the first to colonise the intestine of the infant, preventing the establishment and proliferation of pathogenic bacteria, promoting the development of innate immunity and, therefore, reducing the risk of $\mathrm{NEC}^{(5)}$. In special situations, such as VLBW infants admitted to intensive care units, there may be low levels of colonisation by Bifidobacterium and Lactobacillus, with intestinal microflora being modified towards the higher levels of Klebsiella, Enterobacter, Citrobacter and Pseudomonas that are commonly encountered in hospitals ${ }^{(6)}$.
The stability of the neonatal intestine ecosystem depends on interbacterial cooperation and on the availability of a source of nutrients that is constant in composition and quantity. The bacterial members of indigenous microflora may be modulated by the varying composition of ingested nutrients. The administration of antibiotics to neonates upsets the balance of intestinal flora and may predispose them to episodes of infectious disease. In such cases, according to the available evidence ${ }^{(7)}$, the administration of probiotics can restore the balance of intestinal flora.

Each probiotic strain of a species may have unique properties and different physiological functions. Opinions vary as to the optimum dosages of probiotics. The dosages on which there is greatest consensus include Lactobacillus rhamnosus GG ( $L G G)$; Lactobacillus acidophilus and Bifidobacterium infantis ${ }^{(8)}$. Recent systematic reviews on the use of probiotics in VLBW neonates have reported an OR for enterocolitis of $0.32(95 \% \mathrm{CI}$ $0.17,0.60)$ and that for death of 0.43 (95\% CI $0.25,0.75)$. In view of these findings, the use of probiotics has become a generalised recommendation for this group of infants ${ }^{(9)}$. The Spanish Society of Neonatology, through its Neonatal

Abbreviations: LGG, Lactobacillus rhamnosus GG; NEC, necrotising enterocolitis; VLBW, very low birth weight.

* Corresponding author: Professor J. Uberos, email juberos@ugr.es 
Metabolism and Nutrition Group, has issued a series of recommendations in this respect ${ }^{(10)}$.

The aim of this study was to determine whether routine probiotic supplementation (RPS) with $L G G$ or L. acidophilus + Lactobacillus bifidum was associated with a reduced risk of NEC $\geq$ Stage II $^{(11)}$ in preterm neonates born at $\leq 32$ weeks' gestation. We hypothesised that the introduction of RPS would significantly reduce NEC $\geq$ Stage II.

\section{Methods}

A retrospective cohort study was designed, comparing two periods - before and after the introduction of probiotic supplementation - for VLBW infants at the Neonatal Intensive Care Unit (NICU) at our hospital (Period I: November 2010-August 2013; Period II: December 2013-July 2016).

\section{Ethical considerations}

Nutritional supplementation with probiotics for VLBW neonates came into routine practice following the publication of guidelines in this respect by the Spanish Society of Neonatology, through its Neonatal Metabolism and Nutrition Group ${ }^{(10)}$. The protocol was approved by the Ethics Committee of the Hospital and all current regulations regarding data confidentiality were complied with.

\section{Criteria for inclusion and exclusion}

The study cohort included all newborns with a gestational age $\leq 32$ weeks and/or birth weight $\leq 1500 \mathrm{~g}$. We differentiated those who were $27-32$ weeks (which is the primary focus of the data) from those who were $<27$ weeks. We excluded infants with severe congential anomalies and especially those with gastrointestinal conditions.

\section{Sample size and power}

The prevalence of NEC in Spain is estimated at $7.5 \%$ of VLBW infants ${ }^{(12)}$. For the present study, assuming an $\alpha$ error of $5 \%$ and a power of $90 \%, 259$ infants are required.

\section{Primary outcome}

The primary outcome was incidence of NEC $\geq$ Stage $\mathrm{II}^{(11)}$.

\section{Secondary outcomes}

Secondary outcomes were death, by any cause, late-onset sepsis with positive blood culture $>72 \mathrm{~h}$ after admission (two positive blood cultures for Staphylococcus epidermidis), age at which full enteral feeding is achieved $(120 \mathrm{ml} / \mathrm{kg}$ per d) and days of parenteral nutrition. All outcomes were monitored until discharge or death during initial hospitalisation. The diagnosis of pneumatosis intestinalis by the attending neonatologist was verified independently by the radiologist on call. In case of disagreement, consensus was reached by group discussion between the neonatal and radiology teams during the weekly rounds, and the final diagnosis was then used for coding in the database.

\section{Enteral and parenteral nutrition}

Enteral and parenteral nutrition was provided in accordance with the recommendations of the Nutrition and Metabolism Group of the Spanish Neonatology Society ${ }^{(10)}$ and the standard protocol of the hospital's Neonatal Unit. Donor breast milk was not available for routine use.

In accordance with the above, all clinically stable newborns were given trophic feeding with breast milk (or otherwise, formula, for premature neonates) at $1 \mathrm{ml} / \mathrm{kg}$ every $3 \mathrm{~h}$, from the 1 st day of life. Enteral nutrition was subsequently increased, as tolerated, at a rate of $15-25 \mathrm{ml} / \mathrm{kg}$ per d until full enteral nutrition was reached. Consideration was given to fortifying the breast milk after reaching feeding volumes exceeding $80 \mathrm{ml} / \mathrm{kg}$ per $\mathrm{d}$; this fortification protocol did not change in Periods I and II. Tolerance to feeding and the presence or absence of bloating were recorded daily. The standard protocol of feeding did not change in the 6 years included in the study.

\section{Protocol for the administration of probiotics}

Two commercial presentations of probiotics were used (they were the products used in the Neonatal Unit at the specified times), with the following dosages: (a) Bivos ${ }^{\circledR}$ (Ferring) containing $L G G$ (ATCC 53103) (109 colony-forming units (CFU)) a daily dose of nine drops every $24 \mathrm{~h}$ was dissolved in $2 \mathrm{ml}$ of (breast or formula) milk and supplied by nasogastric tube ${ }^{(13)}$; (b) Infloran $^{\circledR}$ (Berna Biotech) $250 \mathrm{mg}$ capsules containing $10^{9} \mathrm{CFU}$ L. acidophilus (ATCC 4356) and $10^{9} \mathrm{CFU}$ Bifidobacterium bifidum (ATCC 15696) ${ }^{(14)}$ - a daily dose of one capsule every $12 \mathrm{~h}$ was dissolved in $2 \mathrm{ml}$ of (breast or formula) milk and supplied by nasogastric tube, according to the protocol of our Unit, also used by other authors ${ }^{(15)}$. Probiotic supplementation was started at the first enteral feed of at least $1 \mathrm{ml} /$ bolus and was continued until 35 weeks postmenstrual age or until discharge from the NICU.

\section{Statistics}

Study data were recorded in the e-Health record and in the Neosoft ${ }^{\circledR}$ (Spanish Society of Neonatology) program. The descriptive data were summarised using medians and interquartile ranges for continuous values and frequency distribution for categorical variables. Univariate comparisons for continuous variables were performed using the Mann-Whitney test and by the $\chi^{2}$ test for categorical variables. Values for risk of NEC, mortality and late-onset sepsis were obtained by multiple logistic regression analysis, adjusting for gestational age $\leq 27$ weeks or intra-uterine growth restriction (IUGR: birth weight $<10$ th centile for gestation). Characteristics that differed between study periods and other parameters considered to influence neonatal outcomes (e.g. maternal antenatal antibiotics) were also assessed during modelling. The effects of the study periods were summarised as adjusted OR with 95\% CI. The analysis was conducted on all neonates with $<32$ weeks' gestation, and in a subset of neonates with gestational age $\leq 27$ weeks, who were at a higher risk of NEC. The analysis was performed using IBM SPSS 20.0 for Windows (IBM). 


\section{Reporting}

The Strengthening the Reporting of Observational Studies in Epidemiology checklist for reporting observational studies was used $^{(16)}$.

\section{Results}

A total of 461 newborns were admitted to the NICU at our hospital during the two periods considered. Of these infants, 261 were $<32$ weeks' gestational age and/or $<1500 \mathrm{~g}$ birth weight (Period I $v$. II: $134 v$. 127) (Fig. 1). Probiotics, in either of the two commercial formulations used, were given to eighty-six newborns during Period II. Period II infants who were not dependent on $\mathrm{O}_{2}$, with birth weight close to $1500 \mathrm{~g}$, without antibiotic or infectious risk factors did not receive probiotic supplementation, according to the protocol of our neonatal unit. A total of 20/259 (7.7\%) newborns in Period I and 16/226 (7.0\%) in Period II died. Causes of death included extreme prematurity, brain defects, sepsis and HIV.

Their gestational ages and birth weights were comparable (Table 1). The use of antenatal maternal antibiotics (ampicillin or erythromycin) and the number of births with gestational age $\leq 27$ weeks were comparable in the two periods considered. In all, 84.3 and $85.8 \%$ (Period I $v$. Period II) of the mothers received antenatal steroids, and the rate of twin births (36.6 and 39.4\% in Periods I and II, respectively) was also comparable between the two periods. We also did not observe differences in the days of umbilical channeling between Periods I and II. During Period II, the median birth weight was slightly higher than that recorded during Period I, although within the limits of statistical significance. During Period II, fewer hours of $\mathrm{O}_{2}$ therapy were supplied; although the difference is not statistically significant, this did result in a statistically significant decrease in episodes of mild bronchopulmonary dysplasia and retinopathy of prematurity Stages I and II (Table 1$)^{(17)}$. Of the VLBW infants with NEC $\geq$ Stage II, eleven received breast-feeding compared with nine who received formula milk for premature infants; there were no statistically significant differences.

\section{Outcomes for neonates 27-32 weeks}

Although mortality was slightly lower in Period II (14.9 $v$. $12.6 \%$ ), there was a very significant difference between newborns who received probiotics and those who did not (10.6 v. 2.4\%, without probiotics $v$. with probiotics) after adjusting for IUGR, late-onset sepsis and intraventricular haemorrhage (Table 2). NEC $\geq$ Stage II among the infants who received probiotics decreased significantly $(5 \cdot 3 v .1 \cdot 4 \%$, without probiotics $v$. with probiotics), which highlights the protective effect of probiotics, after adjustment for IUGR and ventilatory support. Likewise, NEC stage IV decreases among VLBW infants receiving probiotics, although without achieving significant differences (Tables 2 and 3). Similar effects were observed for late-onset sepsis; in this case too, probiotics exerted a protective effect, after adjustment for IUGR, ventilatory support and days of admission to the NICU. No significant differences were observed in the age of achieving full enteral nutrition, in the days of parenteral nutrition administered (Table 2) or in breast milk nutrition between the study periods (Table 1).

The incidence of patent ductus arteriosus (left atrium:aortic root ratio $>1.4$ or ductal diameter $>1.5 \mathrm{~mm}$ with a left-right shunt) and the proportion of those who needed treatment did not differ between the two study periods (Table 1).

\section{Outcomes for neonates $\leq 27$ weeks}

In all, 32.4 and $34.5 \%$ of the infants with a gestational age $\leq 27$ weeks died during Periods I and II. However, among those who received probiotics, the figure was significantly lower (45.5 v. 5.3\%) (Table 2). At the limits of statistical significance, the rates of NEC $\geq$ Stage II also decreased $(20.5 v$. $15.8 \%$ ) (Table 2). We observed no difference between Periods I and II, or between infants who received or did not receive supplementation with probiotics, as regards the age of achieving full enteral nutrition or the days of parenteral nutrition (Table 2).

\section{Outcomes for Lactobacillus rhamnosus GG and Lactobacillus bifidum + Lactobacillus acidophilus}

A total of fifty-three VLBW newborns received $L G G$ and thirtythree received the combination of L. bifidum + L. acidophilus, in accordance with the dosing schedule described in the 'Methods' section. Tolerance was similar in both groups, and no side effects related to administration of the probiotics were recorded. Although our comparison of the two groups revealed no

\author{
Period I: November 2010-August 2013 (Before RPS) \\ - All admissions to NICU: 205 \\ - Total gestational age $\leq 32$ weeks or birth weight $\leq 1500$ g: 134 \\ - Total mortality in infants with gestational age $\leq 32$ weeks or birth weight $\leq 1500 \mathrm{~g}: 20$ \\ - Live infants who did not receive probiotics: 114 \\ Period II: December 2013-July 2016 (After RPS) \\ - All admissions to NICU: 256 \\ - Total gestational age $\leq 32$ weeks or birth weight $\leq 1500 \mathrm{~g}: 127$ \\ - Total mortality in infants with gestational age $\leq 32$ weeks or birth weight $\leq 1500 \mathrm{~g}: 16$ \\ - Infants who received probiotics: 86
}

Fig. 1. Patient flow diagram. RPS, routine probiotic supplementation; NICU, Neonatal Intensive Care Unit. 
Table 1. Pregnancy and neonatal characteristics

(Numbers and percentages; medians and interquartile ranges (IQR))

\begin{tabular}{|c|c|c|c|c|c|}
\hline \multirow[b]{2}{*}{ Characteristics } & \multicolumn{2}{|c|}{ Period I ( $n$ 134) } & \multicolumn{2}{|c|}{ Period II ( $n$ 127) } & \multirow[b]{2}{*}{$P$} \\
\hline & $n$ & $\%$ & $n$ & $\%$ & \\
\hline \multicolumn{6}{|l|}{ Maternal } \\
\hline $\mathrm{PIH}$ & 8 & 6.0 & 7 & 5.5 & 0.32 \\
\hline Chorioamnionitis & 24 & $17 \cdot 9$ & 16 & $12 \cdot 6$ & 0.23 \\
\hline Antibiotics & 54 & $40 \cdot 3$ & 59 & 46.5 & 0.31 \\
\hline Glucocorticoids & 113 & $84 \cdot 3$ & 109 & $85 \cdot 8$ & 0.73 \\
\hline PPROM & 32 & $23 \cdot 9$ & 29 & $22 \cdot 8$ & 0.84 \\
\hline Gestation (weeks) & \multirow{3}{*}{\multicolumn{2}{|c|}{$\begin{array}{c}29 \\
27-31\end{array}$}} & \multirow{2}{*}{\multicolumn{2}{|c|}{30}} & 0.06 \\
\hline Median & & & & & \\
\hline IQR & & & & & \\
\hline Gestation $\leq 27$ weeks & 34 & 25.4 & 29 & $22 \cdot 8$ & 0.63 \\
\hline Twin birth & 49 & $36 \cdot 6$ & 50 & 39.4 & 0.64 \\
\hline \multicolumn{6}{|l|}{ Mode of delivery } \\
\hline Caesarean section & 106 & $79 \cdot 1$ & 98 & $77 \cdot 2$ & 0.70 \\
\hline Vaginal & 28 & $20 \cdot 9$ & 29 & $22 \cdot 8$ & \\
\hline \multicolumn{6}{|l|}{ Neonatal } \\
\hline Birth weight (g) & \multirow{2}{*}{\multicolumn{2}{|c|}{1157}} & & 0.05 \\
\hline Median & & & \multirow{2}{*}{\multicolumn{2}{|c|}{$\begin{array}{c}1291 \\
910-1477\end{array}$}} & \\
\hline IQR & \multicolumn{2}{|c|}{$995-1408$} & & & \\
\hline Male & 73 & 54.5 & 79 & $62 \cdot 2$ & 0.20 \\
\hline Apgar $<7$ at $5 \mathrm{~min}$ & 39 & $32 \cdot 0$ & 41 & 35.0 & 0.61 \\
\hline IUGR & 31 & $23 \cdot 1$ & 24 & $24 \cdot 0$ & 0.87 \\
\hline Umbilical channeling (d) & & & & & 0.64 \\
\hline Median & \multirow{2}{*}{\multicolumn{2}{|c|}{$\begin{array}{c}3.5 \\
0.25-6.0\end{array}$}} & \multirow{2}{*}{\multicolumn{2}{|c|}{$\begin{array}{c}4.0 \\
0-6.0\end{array}$}} & \\
\hline IQR & & & & & \\
\hline \multicolumn{6}{|l|}{ Respiratory support } \\
\hline $\mathrm{O}_{2}$ & 104 & $90 \cdot 4$ & 98 & $88 \cdot 3$ & 0.60 \\
\hline CPAP & 86 & 74.8 & 86 & 77.5 & 0.63 \\
\hline Ventilation & 61 & $53 \cdot 0$ & 57 & 51.8 & 0.85 \\
\hline \multicolumn{6}{|l|}{ Duration $(\mathrm{h})$} \\
\hline $\mathrm{O}_{2}$ & \multirow{2}{*}{\multicolumn{2}{|c|}{$\begin{array}{c}552 \\
168-1104\end{array}$}} & & & 0.19 \\
\hline Median & & & & & \\
\hline IQR & & & & & \\
\hline CPAP & & & & & 0.61 \\
\hline Median & & & & & \\
\hline IQR & & & & & \\
\hline Ventilation & & & & & 0.93 \\
\hline Median & & & & & \\
\hline IQR & & & & & \\
\hline Bronchopulmonary dysplas & & & & & \\
\hline Mild & 24 & $20 \cdot 9$ & 13 & 11.9 & 0.03 \\
\hline Moderate & 17 & 14.8 & 14 & $12 \cdot 8$ & 0.33 \\
\hline Severe & 11 & 9.6 & 6 & 5.5 & 0.13 \\
\hline PDA & 24 & 17.9 & 16 & $12 \cdot 7$ & 0.24 \\
\hline Treated & 12 & 9 & 12 & 9.5 & 0.89 \\
\hline IVH & & & & & \\
\hline Grade I-II & 18 & $13 \cdot 5$ & 11 & $9 \cdot 1$ & 0.20 \\
\hline Grade III-IV & 14 & 10.5 & 7 & 5.8 & 0.13 \\
\hline ROP & & & & & \\
\hline Stage I-II & 15 & $12 \cdot 0$ & 2 & 1.6 & 0.001 \\
\hline Stage III & 9 & $7 \cdot 6$ & 5 & 4 & 0.23 \\
\hline Early onset sepsis & 15 & 11.2 & 13 & $10 \cdot 2$ & 0.80 \\
\hline Milk breast-feeding & 84 & 63 & 69 & 55 & 0.12 \\
\hline Length of NICU stay (d) & & & & & 0.66 \\
\hline Median & & & & & \\
\hline IQR & & & & & \\
\hline
\end{tabular}

$\mathrm{PIH}$, pregnancy-induced hypertension; PPROM, preterm pre-labour rupture of membranes; IUGR, intra-uterine growth restriction; CPAP, continuous positive airway pressure; PDA, patent ductus arteriosus; IVH, intraventricular haemorrhage; ROP, retinopathy of prematurity; NICU, Neonatal Intensive Care Unit.

significant differences regarding mortality, NEC or late-onset sepsis, mortality fell and late-onset sepsis was present among those who received the $L$. bifidum $+L$. acidophilus combination. The small number of cases available for the subgroup analysis made this question hard to resolve (Table 3 ).

\section{Safety}

There were no cases of late-onset sepsis or the presence of NEC (in any grade) related to the administration of probiotics. 
Table 2. Outcomes for neonates

(Numbers and percentages; odds ratios and $95 \%$ confidence intervals; medians and interquartile ranges (IQR))

\begin{tabular}{|c|c|c|c|c|c|c|c|}
\hline & \multicolumn{2}{|c|}{ Without probiotics } & \multicolumn{2}{|c|}{ With probiotics } & \multirow[b]{2}{*}{ OR } & \multirow[b]{2}{*}{$95 \% \mathrm{Cl}$} & \multirow[b]{2}{*}{$P$} \\
\hline & $n$ & $\%$ & $n$ & $\%$ & & & \\
\hline \multicolumn{8}{|l|}{ Neonates $27-32$ weeks } \\
\hline Cases $(n)$ & \multicolumn{2}{|c|}{131} & \multicolumn{2}{|c|}{67} & & & \\
\hline Mortality* & 14 & $10 \cdot 6$ & 1 & 1.4 & 0.098 & $0.015,0.619$ & 0.014 \\
\hline $\mathrm{NEC} \geq$ Stage II $\dagger$ & 7 & $5 \cdot 3$ & 1 & 1.4 & 0.205 & $0.048,0.880$ & 0.033 \\
\hline NEC Stage IV $\dagger$ & 3 & $2 \cdot 3$ & 1 & 1.4 & & - & - \\
\hline Late-onset sepsis $\ddagger$ & 19 & 14.5 & 5 & $7 \cdot 4$ & 0.334 & $0.125,0.894$ & 0.029 \\
\hline Age at full feeds (d) & & & & & & & 0.639 \\
\hline Median & \multicolumn{2}{|c|}{12} & \multicolumn{2}{|c|}{10} & & & \\
\hline IQR & \multicolumn{2}{|c|}{$8-17$} & \multicolumn{2}{|c|}{$6-16$} & & & \\
\hline Parenteral nutrition (d) & & & & & & & 0.504 \\
\hline Median & \multicolumn{2}{|c|}{11} & \multicolumn{2}{|c|}{10} & & & \\
\hline IQR & \multicolumn{2}{|c|}{$6-16$} & \multicolumn{2}{|c|}{$7-15$} & & & \\
\hline \multicolumn{8}{|l|}{ Neonates $\leq 27$ weeks } \\
\hline Cases $(n)$ & 44 & 19 & & & & & \\
\hline Mortality* & 20 & 45.5 & 1 & $5 \cdot 3$ & 0.081 & $0.009,0.694$ & 0.022 \\
\hline NEC $\geq$ Stage II $\dagger$ & 9 & 20.5 & 3 & $15 \cdot 8$ & 0.167 & $0.025,1.133$ & 0.067 \\
\hline NEC Stage IV $†$ & 2 & 4.5 & 0 & 0 & & - & - \\
\hline Late-onset sepsisł & 9 & 20.5 & 4 & 21.5 & 0.388 & $0.082,1.835$ & 0.232 \\
\hline Age at full feeds (d) & & & & & & - & 0.851 \\
\hline Median & \multirow{2}{*}{\multicolumn{2}{|c|}{$\begin{array}{c}25 \\
15-37\end{array}$}} & \multirow{2}{*}{\multicolumn{2}{|c|}{$\begin{array}{c}26 \\
16-38\end{array}$}} & & & \\
\hline IQR & & & & & & & \\
\hline Parenteral nutrition (d) & \multicolumn{2}{|c|}{$15-37$} & \multicolumn{2}{|c|}{$16-38$} & & - & 0.151 \\
\hline Median & \multirow{2}{*}{\multicolumn{2}{|c|}{$\begin{array}{c}21 \\
10-33\end{array}$}} & \multirow{2}{*}{\multicolumn{2}{|c|}{$\begin{array}{c}25 \\
18-38\end{array}$}} & & & \\
\hline IQR & & & & & & & \\
\hline
\end{tabular}

NEC, necrotising enterocolitis; IUGR, intra-uterine growth restriction; CPAP, continuous positive airway pressure.

${ }^{*}$ Adjusted for IUGR, early onset sepsis, intraventricular haemorrhage.

† Adjusted for IUGR, CPAP, $\mathrm{O}_{2}$ support.

$\ddagger$ Adjusted for IUGR, CPAP, $\mathrm{O}_{2}$ support and Neonatal Intensive Care Unit stay.

Table 3. Outcomes for Lactobacillus rhamnosus GG (LGG) or Lactobacillus bifidum + Lactobacillus acidophilus (Numbers and percentages; medians and interquartile ranges (IQR))

\begin{tabular}{|c|c|c|c|c|c|}
\hline & \multicolumn{2}{|c|}{$L G G$} & \multicolumn{2}{|c|}{ L. bifidum + L. acidophilus } & \multirow[b]{2}{*}{$P$} \\
\hline & $n$ & $\%$ & $n$ & $\%$ & \\
\hline Cases $(n)$ & & & & & \\
\hline Mortality & 2 & 3.8 & 0 & 0 & 0.262 \\
\hline NEC $\geq$ Stage II & 2 & 3.8 & 2 & $6 \cdot 1$ & 0.794 \\
\hline NEC Stage IV & 1 & 1.8 & 0 & 0 & 0.730 \\
\hline Late-onset sepsis & 7 & 13.2 & 2 & $6 \cdot 1$ & 0.295 \\
\hline Age at full feeds (d) & & & & & 0.714 \\
\hline Median & & & & & \\
\hline IQR & & & & & \\
\hline Parenteral nutrition (d) & & & & & 0.587 \\
\hline Median & & & & & \\
\hline IQR & & & & & \\
\hline
\end{tabular}

NEC, necrotising enterocolitis

\section{Discussion}

Our results show that RPS for VLBW infants with $L G G$ or $L$. bifidus $+L$. acidophilus is associated with a lower frequency of NEC $\geq$ Stage II, fewer episodes of nosocomial sepsis and lower mortality. RPS in infants with a gestational age $\leq 27$ weeks revealed a significant decrease in mortality only in this subgroup.

\section{Necrotising enterocolitis and death}

From an epidemiological standpoint, NEC is related to prematurity (it is inversely proportional to gestational age), enteral nutrition (taking into account the daily volume of enteral feeding, the comparison between breast milk and formula, and the osmolarity of first food) and intestinal colonisation by pathogenic flora (Escherichia coli, Klebsiella, Clostridium perfringens, S. epidermidis and Rotavirus). Fernández-Carrocera et al. ${ }^{(18)}$, in a randomised double-blind clinical trial, to evaluate the efficacy of a multispecies probiotic, which included strains of L. acidophilus and $B$. bifidum, observed no significant reduction in the risk of NEC (at any stage), although the risk of death was significantly reduced. Lin et $a l^{(19)}$, used a multicentre, randomised, doubleblind clinical trial and, as in our study, observed a significant reduction in the risk of $\mathrm{NEC} \geq$ Stage II or death, using a 
combination of $L$. acidophilus and B. bifidum. In a quasiexperimental trial, Samuels et al. ${ }^{(20)}$ observed a protective effect of $L$. acidophilus and B. bifidum against NEC and death in breastfed VLBW infants and noted the low frequency of breast-feeding as the sole method. In our study, the same combination of probiotics was observed to have a protective effect against NEC and death, although here too the rate of use of breast-feeding was much lower than is desirable and below that reported elsewhere ${ }^{(21)}$. In a systematic review, Baucells et al. ${ }^{(22)}$ reported that the best protective effects against NEC and death were obtained with the use of the combination of L. acidophilus and B. bifidum.

A systematic review by Bernardo et $a l^{(8)}$, of eleven clinical trials involving 2887 patients, evaluated the benefits of using probiotics as a preventive against NEC and other morbidities associated with prematurity. Wang et al. ${ }^{(23)}$, in a meta-analysis of twenty randomised clinical trials with a total of 3816 preterm VLBW infants, observed a decreased risk of NEC in those treated with probiotics (relative risk (RR) $0.33 ; 95 \%$ CI 0.24 , $0 \cdot 46$ ) and a decreased risk of death (RR 0.56;95\% CI 0.43, 0.73). The authors did not find probiotic treatment to modify the risk of sepsis (RR $0.90 ; 95 \%$ CI $0 \cdot 71,1 \cdot 15$ ). In this systematic review, although diverse probiotics were used in the different trials, most used a combination of L. acidophilus and B. bifidus.

In our study, in patients supplemented with probiotics, the incidence of NEC, mortality and late-onset sepsis is less than the Vermont Oxford international database/benchmark for the VLBW data set (NEC $3.6 \%$, mortality $3.7 \%$ ) and the Spanish data for NEC $(10 \%)^{(24)}$

\section{Late-onset sepsis}

According to other authors ${ }^{(25)}$, a combination of low-dose probiotics decreases the frequency of late-onset sepsis, and thus would be the preferred approach, rather than single strains. In our view, the choice of strain is of vital importance. In this respect, Jacobs et al. ${ }^{(26)}$, using a combination of B. infantis, Streptococcus thermophilus and Bifidobacterium lactis in VLBW infants, observed no protective effect against late-onset sepsis, although there was some protection against $\mathrm{NEC} \geq$ Stage II. In our study, the subgroup analysis (Table 3), although lacking statistical power, suggested that fewer complications of late-onset sepsis occurred after supplementation with $L$. acidophilus and B. bifidum in comparison with supplementation with $L G G$ alone.

\section{Safety}

In 2004, European Society for Paediatric Gastroenterology, Hepatology and Nutrition (ESPGHAN) recommended the use of probiotics in dietary supplementation for children, but until a few years ago there were doubts about the safety of this type of nutritional supplement in VLBW infants, despite the fact that experimental studies showed them to be effective in reducing mortality and the incidence of $\mathrm{NEC}^{(27)}$. Manzoni et al. ${ }^{(13)}$, in a cohort study of $743 \mathrm{VLBW}$ infants, concluded that $L G G$ at a daily dose of $3 \times 10^{9} \mathrm{CFU}$ during the first 4-6 weeks of life is safe and well-tolerated.

Newborns with a gestational age $\leq 27$ weeks would benefit most from probiotic supplementation. These infants are at greatest risk of developing enterocolitis and, moreover, have a less mature immune system. Although the data available are still insufficient, clinical trials and meta-analyses have already provided sufficient evidence of their usefulness and safety ${ }^{(8)}$. In our own research, the subgroup analyses only revealed a statistical decrease in mortality after supplementation with probiotics.

Only isolated episodes have been reported of sepsis or bacteraemia related to the strains of probiotics administered in high-risk patients - specifically after nutritional supplementation with $L G G^{(28,29)}$ - but to date no references exist concerning the development of sepsis or bacteraemia related to L. acidophilus or B. bifidum.

Selection of the appropriate strain or strains would avoid possibly harmful side effects, and enable researchers to focus on the prevention of harmful metabolic activities, systemic infections and adverse effects on immunomodulation and gene transfer ${ }^{(30)}$. In the coming years, it will be necessary to select and study new strains with a better safety profile, rather than others, which, in view of the results obtained, appear to be less safe. It may also be of interest to investigate the efficacy of probiotics along with other protective factors in the prophylaxis of NEC such as donated milk ${ }^{(31)}$ or lactoferrin ${ }^{(32)}$.

\section{Conclusions}

We can conclude from our observations that probiotic supplementation may be indicated in preterm infants of 27-32 weeks of gestational age to reduce mortality, NEC and late sepsis. In preterm infants $<27$ weeks of gestational age, more studies are needed.

\section{Acknowledgements}

The authors thank all the staff of the NICU of the Hospital Clínico San Cecilio de Granada (Spain).

This research received no specific grant from any funding agency, commercial or not-for-profit sectors.

J. U. designed the study and was the study coordinator; J. U. and E. N.-L. carried out the study; E. A.-R. and M. M.-O. analysed the data; E. A.-R., A. J.-C. and A. M.-C. wrote the article.

None of the authors has any conflicts of interest to declare.

\section{References}

1. Schmolzer G, Urlesberger B, Haim M, et al. (2006) Multimodal approach to prophylaxis of necrotizing enterocolitis: clinical report and review of literature. Pediatr Surg Int 22, 573-580.

2. Kafetzis DA, Skevaki C \& Costalos C (2003) Neonatal necrotizing enterocolitis: an overview. Curr Opin Infect Dis 16, 349-355.

3. Asztalos EV, Murphy KE, Willan AR, et al. (2013) Multiple courses of antenatal corticosteroids for preterm birth study: outcomes in children at 5 years of age (MACS-5). JAMA Pediatr 167, 1102-1110.

4. Hwang YS, Ma MC, Tseng YM, et al. (2013) Associations among perinatal factors and age of achievement of full oral feeding in very preterm infants. Pediatr Neonatol $\mathbf{5 4}$, 309-314. 
5. Bry L, Falk PG, Midtvedt T, et al. (1996) A model of hostmicrobial interactions in an open mammalian ecosystem. Science 273, 1380-1383.

6. Goldmann DA, Leclair J \& Macone A (1978) Bacterial colonization of neonates admitted to an intensive care environment. J Pediatr 93, 288-293.

7. Cilieborg MS, Boye M \& Sangild PT (2012) Bacterial colonization and gut development in preterm neonates. Early Hum Dev 88, Suppl. 1, S41-S49.

8. Bernardo WM, Aires FT, Carneiro RM, et al. (2013) Effectiveness of probiotics in the prophylaxis of necrotizing enterocolitis in preterm neonates: a systematic review and meta-analysis. J Pediatr (Rio J) 89, 18-24.

9. Alfaleh K, Anabrees J, Bassler D, et al. (2011) Probiotics for prevention of necrotizing enterocolitis in preterm infants. The Cochrane Database of Systematic Reviews 2011, issue 3, CD005496.

10. Narbona LE, Uberos FJ, Armada Maresca MI, et al. (2014) Nutrition and Metabolism Group of the Spanish Neonatology Society: recommendations and evidence for dietary supplementation with probiotics in very low birth weight infants. An Pediatr (Barc) 81, 397-398.

11. Bell M, Ternberg JL, Feigin RD, et al. (1978) Neonatal necrotizing enterocolitis. Therapeutic decisions based upon clinical staging. Ann Surg 187, 1-7.

12. De La Torre CA, Miguel M, Martinez L, et al. (2010) The risk of necrotizing enterocolitis in newborns with congenital heart disease. a single institution-cohort study. Cir Pediatr 23, 103-106.

13. Manzoni P, Lista G, Gallo E, et al. (2011) Routine Lactobacillus rhamnosus GG administration in VLBW infants: a retrospective, 6-year cohort study. Early Hum Dev 87, Suppl. 1, S35-S38.

14. European Medicines Agency (2014) Orphan Drug Designation for Lactobacillus acidophilus and Bifidobacterium bifidum for the prevention of necrotising enterocolitis. Patent no. EU/ 3/13/1213, European Medicines Agency. http://www.ema. europa.eu/docs/en_GB/document_library/Orphan_designation/ 2014/01/WC500159907.pdf

15. Repa A, Thanhaeuser M, Endress D, et al. (2015) Probiotics (Lactobacillus acidophilus and Bifidobacterium infantis) prevent NEC in VLBW infants fed breast milk but not formula [corrected]. Pediatr Res 77, 381-388.

16. von EE, Altman DG, Egger M, et al. (2007) The Strengthening the Reporting of Observational Studies in Epidemiology (STROBE) statement: guidelines for reporting observational studies. Ann Intern Med 147, 573-577.

17. Garcia-Serrano JL, Uberos FJ, Anaya-Alaminos R, et al. (2013) 'Oxygen with love' and diode laser treatment decreases comorbidity and avoidable blindness due to retinopathy of prematurity: results achieved in the past 12 years. Pediatr Neonatol 54, 397-401.

18. Fernández-Carrocera LA, Solis-Herrera A, et al. (2013) Double-blind, randomised clinical assay to evaluate the efficacy of probiotics in preterm newborns weighing less than $1500 \mathrm{~g}$ in the prevention of necrotising enterocolitis. Arch Dis Child Fetal Neonatal Ed 98, F5-F9.

19. Lin HC, Hsu CH, Chen HL, et al. (2008) Oral probiotics prevent necrotizing enterocolitis in very low birth weight preterm infants: a multicenter, randomized, controlled trial. Pediatrics 122, 693-700.

20. Samuels N, van de Graaf R, Been JV, et al. (2016) Necrotising enterocolitis and mortality in preterm infants after introduction of probiotics: a quasi-experimental study. Sci Rep 6, 31643.

21. Patole SK, Rao SC, Keil AD, et al. (2016) Benefits of Bifidobacterium breve M-16V supplementation in preterm neonates a retrospective cohort study. PLOS ONE 11, e0150775.

22. Baucells BJ, Mercadal HM, Alvarez Sanchez AT, et al. (2015) Probiotic associations in the prevention of necrotising enterocolitis and the reduction of late-onset sepsis and neonatal mortality in preterm infants under 1,500g: a systematic review. An Pediatr (Barc) 85, 247-255.

23. Wang Q, Dong J \& Zhu Y (2012) Probiotic supplement reduces risk of necrotizing enterocolitis and mortality in preterm very low-birth-weight infants: an updated metaanalysis of 20 randomized, controlled trials. J Pediatr Surg 47, 241-248

24. Murphy BP, Armstrong K, Ryan CA, et al. (2010) Benchmarking care for very low birthweight infants in Ireland and Northern Ireland. Arch Dis Child Fetal Neonatal Ed 95 , F30-F35.

25. Kanic Z, Micetic TD, Burja S, et al. (2015) Influence of a combination of probiotics on bacterial infections in very low birthweight newborns. Wien Klin Wochenschr 127, Suppl. 5, S210-S215.

26. Jacobs SE, Tobin JM, Opie GF, et al. (2013) Probiotic effects on late-onset sepsis in very preterm infants: a randomized controlled trial. Pediatrics 132, 1055-1062.

27. Barclay AR, Stenson B, Simpson JH, et al. (2007) Probiotics for necrotizing enterocolitis: a systematic review. I Pediatr Gastroenterol Nutr 45, 569-576.

28. Dani C, Coviello CC, Corsini I, et al. (2016) Lactobacillus sepsis and probiotic therapy in newborns: two new cases and literature review. AJP Rep 6, e25-e29.

29. Ohishi A, Takahashi S, Ito Y, et al. (2010) Bifidobacterium septicemia associated with postoperative probiotic therapy in a neonate with omphalocele. J Pediatr 156, 679-681.

30. Marteau PR (2002) Probiotics in clinical conditions. Clin Rev Allergy Immunol 22, 255-273.

31. Williams AF, Kingdon CC \& Weaver G (2007) Banking for the future: investing in human milk. Arch Dis Child Fetal Neonatal Ed 92, F158-F159.

32. Pammi M \& Abrams SA (2015) Oral lactoferrin for the prevention of sepsis and necrotizing enterocolitis in preterm infants. The Cochrane Database of Systematic Reviews 2015, issue 2, CD007137. 